\title{
In vitro Algaecide Effect of Disinfectants on Prototheca zopfii Genotypes 1 and 2
}

\author{
Hideto SOBUKAWA ${ }^{1)}$, Mitsuhiro WATANABE ${ }^{1)}$, Rui $\mathrm{KANO}^{1) *}$, Takaaki ITO $^{2)}$, Masanobu ONOZAKI ${ }^{3)}$, \\ Atsuhiko HASEGAWA ${ }^{4)}$ and Hiroshi KAMATA ${ }^{1)}$ \\ ${ }^{1)}$ Department of Pathobiology, Nihon University School of Veterinary Medicine, 1866 Kameino, Fujisawa, Kanagawa 252-0880, \\ ${ }^{2)}$ Livestock Medical Center, Aichi P.F.A.M.A.A, 165 Miyawaki, Baba, Toyokawa, Aichi 442-0811, ${ }^{3}$ Kanto Chemical Co., Inc., Marusan \\ Building, 3-11-5, Nihonbashi Honcho, Chuo-ku, Tokyo 103-0023 and " Teikyo University Institute of Medical Mycology, 539 Otsuka, \\ Hachioji, Tokyo 192-0395, Japan
}

(Received 31 May 2011/Accepted 26 June 2011/Published online in J-STAGE 8 July 2011)

ABSTRACT. Bovine mastitis due to Prototheca zopfii leads to reduced milk production and is difficult to cure. Therefore, prevention is the best approach and this is best achieved through the use of effective disinfectants. The aim of this study was to evaluate the in vitro algaecide efficacy of conventional disinfectants against strains of $P$. zopfii genotype 1 and 2 . The minimal algaecide concentration (MAC) of alkyldiaminoethylglycine hydrochloride, chlorhexidine, dioxide chlorine, povidone iodine and sodium hypochlorous acid against 10 isolates and the type strain $\left(\mathrm{SAG} 2063^{\mathrm{T}}\right)$ of $P$. zopfii genotype 1 as well as 10 isolates and the type strain $\left(\mathrm{SAG} 2021^{\mathrm{T}}\right)$ of $P$. zopfii genotype 2 were examined using the micro dilution method. This in vitro study indicated that alkyldiaminoethylglycine hydrochloride, chlorhexidine, povidone iodine and sodium hypochlorous acid, but not dioxide chlorine, are effective against both genotypes of P. zopfii.

KEY WORDS: disinfectants, genotype, mastitis, Prototheca zopfii.

J. Vet. Med. Sci. 73(11): 1527-1529, 2011

Bovine mastitis due to Prototheca zopfii leads to reduced milk production and thin watery milk secretion containing white flakes. P. zopfii has been classified biochemically and serologically into genotypes 1 and 2, and Prototheca blaschkeae $[1,5,6]$. According to the latest genotypic classification, all isolates from bovine mastitis in Germany and Japan were $P$. zopfii genotype 2, suggesting that genotype 2 is the principal causative agent of bovine protothecal mastitis $[2,3]$.

In our previous in vitro study, the sensitivity of $P$. zopfii genotype 2 isolates was shown to be lower to conventional antimicrobial and antifungal drugs than that of genotype 1 [8]. Currently, bovine mastitis due to Prototheca is a chronic infection with no effective treatments. Therefore, suitable antimicrobial drugs or disinfectants are required to prevent bovine Protothecal mastitis. The aim of this study was to evaluate the in vitro algaecide effects of conventional disinfectants against $P$. zopfii genotype 1 and 2 strains.

The type strain of genotype $1\left(\mathrm{SAG} 2063^{\mathrm{T}}\right)$ and the type strain of genotype $2\left(\mathrm{SAG} 2021^{\mathrm{T}}\right)$ from $P$. zopfii were used for susceptibility tests.

In addition to the type strains, 10 isolates of $P$. zopfii genotype 2 from 10 cases of bovine protothecal mastitis in Japan and 10 isolates of $P$. zopfii genotype 1 from Japanese stock farm were examined $[5,8]$. These isolates were previously identified by an $18 \mathrm{~S}$ rDNA-based genotype-specific PCR assay [2, 3, 5] (Table 1).

The disinfectants alkyldiaminoethylglycine hydrochloride, chlorhexidine, dioxide chlorine, povidone iodine and

\footnotetext{
* Correspondence to: Kano, R., Department of Pathobiology, Nihon University School of Veterinary Medicine, 1866 Kameino, Fujisawa, Kanagawa 252-0880, Japan. e-mail: kano@brs.nihon-u.ac.jp
}

sodium hypochlorous acid were analyzed for their minimal microbicidal concentration (MMC) (M27-A2) [9] using the micro dilution test with some modifications. The minimal algaecide concentration (MAC) of isolates was defined as the lowest disinfectant concentration able to prevent postexposure algae growth in RPMI 1640 with compound 3-(Nmorpholino) propanesulfonic acid (MOPS) [9].

Stock inoculum suspensions were prepared from 3-dayold cultures grown on yeast and mould agar (Oxoid, Ltd., Hampshire, UK) at $37^{\circ} \mathrm{C}$, and were adjusted spectrophotometrically to optical densities that ranged from OD 0.8 to $1.0\left(\mathrm{OD}_{600}\right)$ in sterile $0.9 \%$ saline. The final concentrations of the inoculums were diluted 1,000 times $\left(2.3 \times 10^{5}\right.$ to 3.1 $\times 10^{5} \mathrm{CFU} / \mathrm{m} l$ ) with RPMI 1640 .

The concentrations of the disinfectants were $5 \times 10^{-9}$ to 5 $\mu \mathrm{g} / \mathrm{m} l$ for alkyldiaminoethylglycine hydrochloride and chlorhexidine, 0.094 to $48 \mu \mathrm{g} / \mathrm{m} l$ for dioxide chlorine $\left(\mathrm{ClO}_{2}\right), 0.012$ to $10 \mu \mathrm{g} / \mathrm{m} l$ for povidone iodine and $6 \times 10^{-9}$ to $6 \mu \mathrm{g} / \mathrm{m} l$ for sodium hypochlorous acid $(\mathrm{NaClO})$. The concentrations of the disinfectants are according to general use as disinfection at hospitals and dairy farms.

After a $48-\mathrm{hr}$ incubation at $32^{\circ} \mathrm{C}$, visual reading of wells was performed and the growth of each strain at various concentrations of the disinfectants was recorded. As the control, each of the 22 isolates was grown in drug-free medium and resultant growth recorded. The MAC of an isolate was defined as the concentration of the agent at which $90 \%$ of growth was inhibited $\left(\mathrm{MAC}_{90}\right)$. The experiments were performed in triplicate for each isolate on separate occasions. Agreement was evaluated by MAC endpoint discrepancies of no more than two dilutions.

For all isolates of genotype 1 , the $\mathrm{MAC}_{90}$ was $3.13 \times 10^{-}$ ${ }^{3} \mu \mathrm{g} / \mathrm{m} l$ (range, $5.0 \times 10^{-4}$ to $5.0 \times 10^{-3} \mu \mathrm{g} / \mathrm{m} l$ ) for alkyl- 
Table 1. Strains used in this study

\begin{tabular}{clclcc}
\hline Strains & Origin & Genotype & Strains & Origin & Genotype \\
\hline NUBS5 & Bovine mastitis & 2 & NUBS68 & Feces & 1 \\
NUBS19 & Bovine mastitis & 2 & NUBS88 & Feces & 1 \\
NUBS26 & Bovine mastitis & 2 & NUBS133 & Feces & 1 \\
NUBS44 & Bovine mastitis & 2 & NUBS150 & Feces & 1 \\
NUBS50 & Bovine mastitis & 2 & NUBS163 & Feces & 1 \\
NUBS51 & Bovine mastitis & 2 & NUBS21 & Drinking water & 1 \\
NUBS89 & Bovine mastitis & 2 & NUBS41 & Drinking water & 1 \\
NUBS101 & Bovine mastitis & 2 & NUBS70 & Drinking water & 1 \\
NUBS114 & Bovine mastitis & 2 & NUBS178 & Rat & 1 \\
NUBS184 & Bovine mastitis & 2 & NUBS73 & Sewage & 1 \\
\hline
\end{tabular}

diaminoethylglycine hydrochloride, $3.13 \times 10^{-3} \mu \mathrm{g} / \mathrm{ml}$ (range, $2.5 \times 10^{-4}$ to $2.5 \times 10^{-2} \mu \mathrm{g} / \mathrm{m} l$ ) for chlorhexidine, 60 $\mu \mathrm{g} / \mathrm{ml}$ (range, 30 to $120 \mu \mathrm{g} / \mathrm{m} l$ ) for dioxide chlorine, 1.17 $\mu \mathrm{g} / \mathrm{m} l$ (range: 0.78 to $3.13 \mu \mathrm{g} / \mathrm{m} l$ ) for povidone iodine, and $0.069 \mu \mathrm{g} / \mathrm{ml}$ (range: $3 \times 10^{-3}$ to $0.3 \mu \mathrm{g} / \mathrm{m} l$ ) for sodium hypochlorous acid.

For all isolates of genotype 2, the $\mathrm{MAC}_{90}$ was $1.65 \times 10^{-3}$ $\mu \mathrm{g} / \mathrm{ml}$ (range, $5.0 \times 10^{-4}$ to $5.0 \times 10^{-3} \mu \mathrm{g} / \mathrm{ml}$ ) for alkyldiaminoethylglycine hydrochloride, $1.72 \times 10^{-3} \mu \mathrm{g} / \mathrm{m} l$ (range, 2.5 $\times 10^{-5}$ to $\left.2.5 \times 10^{-2} \mu \mathrm{g} / \mathrm{m} l\right)$ for chlorhexidine, $51.5 \mu \mathrm{g} / \mathrm{ml}$ (range, 15 to $120 \mu \mathrm{g} / \mathrm{m} l$ ) for dioxide chlorine, $1.63 \mu \mathrm{g} / \mathrm{ml}$ (range: 0.39 to $3.13 \mu \mathrm{g} / \mathrm{m} l$ ) for povidone iodine, and 0.12 $\mu \mathrm{g} / \mathrm{ml}$ (range: $3 \times 10^{-3}$ to $0.3 \mu \mathrm{g} / \mathrm{m} l$ ) for sodium hypochlorous acid.

These in vitro findings indicate that alkyldiaminoethylglycine hydrochloride, chlorhexidine, povidone iodine and sodium hypochlorous acid are effective against both genotypes of $P$. zopfii while dioxide chlorine is not. We recognized that alkyldiaminoethylglycine hydrochloride, chlorhexidine, povidone iodine and sodium hypochlorous are algaecidal against $P$.zopfii (data were not shown).

In Japan, sodium hypochlorous acid disinfectant is widely used in dairy farms for the disinfection of floors, walls, utensil and equipment. In the present study, we found that sodium hypochlorous acid should be used at a concentration of $>0.3 \mu \mathrm{g} / \mathrm{ml}(0.03 \%)$ to be effective. Povidone iodine is generally used in pre- and post-dipping antisepsis of mammary glands, and was found to be effective at 0.39 to $3.13 \mu \mathrm{g} / \mathrm{ml}$ (more than $0.313 \%$ ) in this study. Salerno et al. also reported that a low concentration of sodium hypochlorite $(0.15625 \%)$ and iodine $(0.625 \%)$ is effective against $P$. zopfii [7].

The antiseptic effect of chlorhexidine against both genotypes of $P$. zopfii was higher than that of sodium hypochlorous acid or povidone iodine. Our findings suggest that chlorhexidine at a concentration of $>2.5 \times 10^{-2} \mu \mathrm{g} / \mathrm{ml}$ $(0.0025 \%)$ would provide effective antiseptic dipping.

The alkyldiaminoethylglycine hydrochloride has not been used in dipping antisepsis of mammary glands in Japan. However, this antiseptic at a concentration of $>5.0 \times$ $10^{-3} \mu \mathrm{g} / \mathrm{m} l(0.0005 \%)$ would provide effective against $P$. zopfii genotype 2 . This antiseptic has been widely used in various fields including human and small animal medicines.
It needs more consideration for this antiseptic in livestock.

In our previous study, $P$. zopfii genotype 2 was more resistant to amphotericin $\mathrm{B}$, gentamicin and kanamycin than P. zopfii genotype 1 [8]. Moreover, genotype 2 isolates and 7 isolates of genotype 1 , including the type strain, were resistant to itraconazole (MIC $>10 \mu \mathrm{g} / \mathrm{m} l$ ) [8]. Therefore, disinfectants should be further examined with a view to developing more effective antimicrobial and antifungal drugs for the control of bovine mammary protothecosis in dairy farms.

ACKNOWLEDGMENTS. This study was supported by Grants-in-Aid for Scientific Research (C) (22580368) from the Academic Frontier Project of the Japanese Ministry of Education, Culture, Sports, Science and Technology (MEXT), and from Nihon University.

\section{REFERENCES}

1. Blaschke-Hellmessen, R., Schuster, H. and Bergmann, V. 1985. Differenzierung von Varianten bei Prototheca zopfii (Krüger 1894). Arch. Exp. Veterinärmed. 39: 387-397.

2. Möller, A., Truyen, U. and Roesler, U. 2007. Prototheca zopfii genotype 2 -the causative agent of bovine protothecal mastitis? Vet. Microbiol. 120: 370-374.

3. Osumi, T., Kishimoto, Y., Kano, R. et al. 2008. Prototheca zopfii genotypes isolated from cow barns and bovine mastitis in Japan. Vet. Microbiol. 131: 419-423.

4. Pore, R.S. 1973. Selective medium for the isolation of Prototheca. Appl. Microbiol. 26: 648-649.

5. Roesler, U., Möller, A., Hensel, A., Baumann, D. and Truyen, U. 2006. Diversity within the current algal species Prototheca zopfii: a proposal for two Prototheca zopfii genotypes and description of a novel species, Prototheca blaschkeae sp. nov. Int. J Syst. Evol. Microbiol. 56: 1419-1425.

6. Roesler, U., Scholz, H. and Hensel, A. 2003. Emended phenotypic characterization of Prototheca zopfii: a proposal for three biotypes and standards for their identification. Int. J. Syst. Evol. Microbiol. 53: 1195-1199.

7. Salerno, T., Garcia, M., Langoni, H., Siqueira, A.K. and da Costa, E.O., Melville, P.A., Bueno, V.F.F. 2010. In vitro algaecide effect of sodium hypochlorite and iodine based antiseptics on Prototheca zopfii strains isolated from bovine milk. Res. Vet. Sci. 88: 211-213.

8. Sobukawa, H., Watanabe, M., Kano, R., Ito, T., Onozaki, M., Hasegawa, A. and Kamata, H. 2010. In vitro susceptibility of 
Prototheca zopfii genotypes 1 and 2. Med. Mycol. 49: 222-224.

9. Wayne, P.A. 2002. NCCLS; National Committee for Clinical and Laboratory Standards. Reference method for broth dilution antifungal susceptibility testing of yeasts. Approved standard M27-A2, National Committee for Clinical Laboratory Standards. 